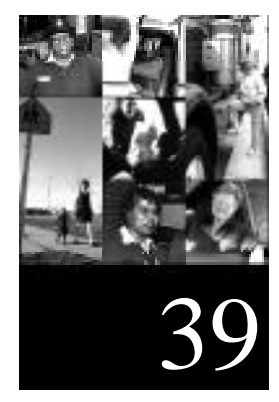

\title{
Automobile Insurance Pricing: Operating Cost versus Ownership Cost; the Implications for Women
}

Patrick Butler 


\title{
AUTOMOBILE INSURANCE PRICING: OPERATING COST VERSUS OWNERSHIP COST; THE IMPLICATIONS FOR WOMEN
}

\begin{abstract}
This paper assesses the ability of automobile insurance prices to distinguish the 2:1 ratio of men's to women's annual mileage, which is linked to a similar ratio of accident involvement per year. Review of current price classes by driver sex and age, by future mileage, and by past driver record reveals severe limitations to their capacity to assess women's lower mileage exposure to risk of accidents. Accidents are modeled as a process of random sampling of vehicle miles traveled (VMT) by cars in an insurance class. This analogy underscores 1) the impossibility of pricing by individual accident record and 2) the paramount importance of odometer-measured vehicle miles of on-the-road exposure for assessing individual accident risk in money terms.
\end{abstract}

The need for risk classification as the essential complement to exposure measurement is shown by considering how a single insurance surcharge on gasoline ("pay at the pump" insurance) as an exposure measure would perversely affect incentives for risk control. Current risk classification is profoundly compromised because individual exposure is not measured. An efficient per-mile premium system combining exposure measurement and risk classification is described. Current flat premiums are compared to premiums that would increase in direct proportion to miles of driving exposure. This comparison shows how individuals, and also women and men as groups, would be affected by changing insurance from a fixed cost of car ownership to a per-mile operating cost of car use.

\section{INTRODUCTION}

As a fixed cost of car ownership, automobile insurance currently competes for financial resources with car payments, registration fees, and property taxes. If we were to make insurance a per-mile cost of driving, however, operating costs, which now are dominated by gasoline, would approximately double. Why make such a change? Two reasons are obvious: to enhance affordability and to reduce externalization of accident costs. A third and less obvious reason is suggested by the fact that this change would reduce annual ownership cost by several hundred to several thousand dollars for all drivers and cause operating cost to increase by a similar range in amount. We will see, however, that the insurance increase in operating cost for most drivers would either be greater or less but not the same as the insurance decrease in their ownership cost. An important political question is which groups would spend more for insurance and which would spend less than they do now.

A more fundamental question, however, is which system-fixed cost or operating cost-can more accurately measure and charge for the risk of driving an automobile. Economists generally agree that insurance cost pressure should provide individuals with incentives to control accident risk (Williamson et al., 1967, Vickrey, 1968, Calabresi, 1970). We will consider how well the current system provides this risk control function and whether a change to per-mile charges would do a better job. 
Insurance would be changed to an operating cost if mandated by a one-sentence amendment to insurance rate regulation law, introduced but not enacted several years ago in Pennsylvania (Butler, 1993a, National Organization for Women, 1998) and proposed in other states. The amendment would require companies to convert their price unit-and thus their cost unit-from dollars per vehicle year to cents per vehicle mile. But what would this change mean for women?

This question is especially relevant since the system now in use has been defended for several decades as a benefit to women and used to justify resistance to any civil rights measure to prohibit pricing by driver sex (recently by Brown, 1995, but see also Butler, 1995). As a lower mileage group, women might on average spend less for auto insurance, but insurers argue that price classes are already tied to the annual mileage of cars and also to women's lower accident involvement and better driving records. Therefore, we will start with an examination of the current class system and its capabilities.

\section{INSURANCE CLASSES}

The car, not the driver, is the unit of insurance. To analyze costs and set prices, insurers categorize cars according to six kinds of classes: territory, type of car, declared future use of car (such as driving to work), type of driver, declared future mileage (Butler et al., 1988), and past driver record (Butler and Butler, 1989). In practice, they assign a base price by coverage (liability, collision, etc.) to each territory class according to past costs. The other five kinds of classes supply additions to and subtractions from a base 1.00 multiplier of the territory price. If converted to the vehicle mile unit, territory base prices could be adjusted by vehicle weight and other important risk attributesclassifications not now used-to serve important risk evaluation functions. Before discussing these functions, however, we will look more closely at the classes involving drivers and mileage that insurers represent as beneficial to women.

\section{DRIVER SEX AND AGE CLASSES}

Classification of cars by type of driver uses sex and age to define three kinds of subclasses: young men, young women, and unisex adult. According to annual police reports, men's accident involvement per 100 licensed drivers is about twice women's in each age group. Strikingly inconsistent with this pattern, however, is the insurance switch from sex-specific to unisex pricing for almost all cars with drivers more than 25 or 30 years old (Butler et al., 1988, p. 251).

Table 1 shows typical prices for cars assigned by driver age to unisex and sex specific classes. Insurance for cars driven by young men is about 1.6 times the price for cars driven by young women, and both are higher than the unisex prices. Since these prices approximate the ratio of men's to women's annual mileage, however, young men and women on average—but not individually—spend about the same amount per mile for insurance. As emphasized in Table 1, for example, young women who drove 5,000 miles in a year paid 15 cents per mile while young men who drove 10,000 miles paid 14 cents per mile. Although all cars are classified by driver age, fewer than one in four cars are classified by driver sex. 
Table 1

Insurance Prices and Costs by Driver Sex and Age, and Car Miles per Year

\begin{tabular}{|l|c|c|c|c|c|c|}
\hline \hline & \multicolumn{2}{|c|}{$\begin{array}{c}\text { Class Multiplier } \\
\text { by Future } \\
\text { Driver Class }\end{array}$} & $\begin{array}{c}\text { Vehicle-Year } \\
\text { Price (\$) for } \\
\text { Mileage Class* }\end{array}$ & \multicolumn{3}{|c|}{$\begin{array}{c}\text { Vehicle-Mile Cost } \\
\text { High Future } \\
\text { (Cents) to Owner by } \\
\text { Miles Actually Driven in Year }\end{array}$} \\
\cline { 7 - 8 } Men 17-24 & Low & High & Mileage** & 5,000 mi. & 10,000 mi. & 20,000 mi. \\
\cline { 2 - 3 } Women 17-24 & 2.35 & 2.80 & 1400 & 23.5 & $\mathbf{1 4 . 0}$ & 7.0 \\
Unisex 30+ & 1.50 & 1.70 & 850 & $\mathbf{1 5 . 0}$ & 8.5 & 4.3 \\
\hline
\end{tabular}

* State Farm California manual effective 1-15-91.

** Territory base price assumed to be $\$ 500$.

If insurers kept claim costs for cars with adult drivers separately for men and women, as they do for young drivers, non-insurance mileage and accident statistics indicate that the price for adult men would be about $40 \%$ above the current unisex price and the price for adult women would be about $30 \%$ below it (Butler et al., 1988). This is not an argument for expanding discrimination between men and women to include all cars instead of a small minority of them. Nevertheless, since a large majority of cars are classified as unisex, one can reasonably ask how the real difference between men's and women's average mileages for these cars is expressed in insurance prices? Why is the cost difference ostentatiously responded to in youth cars and ignored in the far larger group of adult cars? Even if all cars were classified by the sex of a driver, however, many men drive fewer miles in a year than women's average and some women drive more miles in a year than men's average. Therefore, driver sex fails at all ages as a measure for the miles individual cars travel.

\section{FUTURE MILEAGE CLASSES}

Insurers profess to take individual vehicle miles traveled (VMT) into account by offering price classes that are defined in terms of annual mileage, which they call "mileage rating." By requesting odometer readings on application and renewal forms, they encourage the driving public to assume mistakenly that mileage driven has a significant effect on premium amount. However, company rate and rule manuals define a car's annual mileage by how far it will be driven in the coming year-that is, future mileage - as stated by the insured (or filled in by the agent). At the end of the policy year, there is no premium adjustment regardless of how many or few miles a car actually was driven. Predictably, the resulting price differences between low and high future mileage classes conform to nominal discount or surcharge amounts of 15 to 20 percent. Some companies have even discontinued low future mileage discounts entirely because of the inherent impossibility under the pressure of price competition on agents of keeping a large majority of drivers from getting such discounts (Butler et al., 1988, pp. 388-393). Since neither future mileage nor driver sex comes close to pricing the differences between the average accident involvements and annual mileages of men and women, we turn to driver record as the third and last kind of class pricing that insurers say helps to distinguish these major differences.

\section{DRIVER RECORD CLASSES}

The familiar advertisements that offer "good rates for good drivers" promote the mistaken idea that individual risk can be measured by a driver's accident record. Although the idea is quietly disparaged by some company actuaries, the public only hears the marketing department's message. Probability 
modeling by industry actuaries that treats traffic accidents as a random process, however, shows that this popular idea is erroneous (Industry Advisory Committee 1979, Butler and Butler, 1989, Butler, 1993b). A simple thought-experiment explains why. Imagine a jar containing 100 black balls representing individual cars. Draw out one ball at random to represent an accident involvement, and then replace it in the jar and stir before the next drawing. To keep track of the accident record of individual balls, change the color of a drawn ball before replacing it from black to white (first accident), then from white to green if drawn a second time, then from green to red for a third draw of the same ball. Since 100 insured cars typically produce 5 claims a year and since insurers use the records of the past three years to determine surcharges, draw and replace 15 balls. Then count the balls by color. Poisson probability predicts that about 86 of the balls will still be black (accident free), 13 white ( 1 accident), 1 green ( 2 accidents), and 0.05 red. If the experiment were scaled up to 10,000 balls - approximately the number of cars actuaries require for a credible risk class-five of them would be red, indicating 3 accidents apiece in a period of three years. Is this proof that some balls are more likely to be drawn than others? Not at all. By design, all of the balls had an equal chance of being picked in each draw.

In defense of classifying cars by accident record, insurance companies point to the well-established fact that the subclass of drivers who had accidents in a three-year period subsequently averages more accidents in the following (fourth) year than accident-free drivers in the same class. This result, however, can be modeled by specifying that not all of the balls spend the same amount of time in the jar and thus have different chances of being drawn (Butler and Butler, 1989, pp. 206-208, Butler, 1993b, pp. 58-60). Rather than appealing to compound Poisson models of balls with different exposures, we can instead think of an accident-record subclass as a random sample of a class of cars on the road.

A three-year's sample of cars picked at random by accident involvement from a class of cars would include cars driven many miles and also cars driven few miles. The cars driven more than the classaverage, however, would be over-represented in the accident sample because they were more exposed to risk of accident, while the cars driven less than average would be under-represented in this sample. In the coming (fourth) year, therefore, the subclass of cars whose drivers have had accidents in the last three years would average a higher mileage and more accidents than the large class of cars with accident-free drivers. An example emphasizes important consequences.

Typically a subclass of cars defined by having had accidents in the past three years, taken from a class with 5 claims a year per 100 cars, subsequently averages about 7.5 claims a year per 100 cars, which is a fifty percent increase. This apparently large increase in accident rate would simply mean that there has been a similar increase in annual mileage, say from a class average of 10,000 miles to an accident subclass average of 15,000 miles. Finally, it is important to realize that despite this large difference in accidents per year between the main accident-free class and the recent-accident subclass, a very large majority of the cars in each would have identical accident-free records in this fourth year: about $93 \%$ in the recent-accident subclass compared with slightly more than $95 \%$ in the rest of the class.

In discussing a paper of mine that made the analogy between accident record classes and random samples biased to higher average mileages, the chief actuary of the Automobile Insurers Bureau in Boston noted that the effect of differences in miles of exposure to risk on the road "is one that I 
expect many practicing actuaries frequently forget" (Cardoso, 1993). He then described an equivalent problem: "If one surveys riders [on the subway] at random and asks how many days per month they ride the subway, the average answer will be too high an estimate of the population mean because the survey-taker more likely will encounter persons who are frequently on the subway."

As with surveying subway riders for riding frequency, if one were to randomly survey cars on the road for annual mileage, the resulting average would be too high an estimate of the population mean for any class of cars. Similarly, an accident sample of cars on the road will not be representative of average mileage of a population of insured cars, but will be biased to cars which are more frequently on the road. In fact, the population that accidents sample at random is not a class of insured cars but rather the total VMT in a year (or other time period) by the cars in the class.

It follows that the measurable protection cost an individual car imposes on the insurance system is not proportional to the amount of time that the insurance is in effect-as insurance is currently costed and priced-but is proportional to the number of miles the car is exposed to risk, which is recorded by its odometer. The car owner exerts absolute control on risk-taking: without exposure there is no chance of accident involvement and no cost to the insurance system. Moreover, VMT of on the road exposure to risk can only be measured individually and not by averages for classes defined by driver sex or by unverifiable declarations of future mileage. Measuring exposure, however, is only one of two parts to the task of evaluating individual risk.

Complementary to measuring individual exposure is the need to determine the risk rate per vehicle mile of exposure for different classes of driving risk. For cars with young drivers the accident sampling rate per VMT is two to four times the rate for cars with adult drivers. The model of balls picked randomly from a jar, however, emphasizes that the sampling rate per VMT is inherently a class property that cannot be measured for individuals.

We will compare current class prices presumed to reflect risk with the risk per VMT that could be derived from direct measurement of exposure by the odometers of all cars in each class. To underscore the importance of classification to measure different risk rates per mile, however, we will first examine an alternative proposal that would proportion premiums to gallons of gasoline.

\section{MEASURING VEHICLE RISK}

\section{MEASURING VEHICLE MILES OF EXPOSURE}

Adding an insurance charge to the price of gasoline is a proposal that has received considerable support from consumer and environmental advocates and some academics (e.g., Sugarman, 1993). Full coverage would probably require about $\$ 1$ per gallon, although proponents are proposing only minimum coverage that would require a lower surcharge. A substantial insurance addition to the price of gasoline would increase the operating cost incentive to reduce risk by driving less. A "payat-the-pump" insurance system, however, would not only eliminate price variation for different car values and optional coverages but, even more seriously, would produce strong incentives for increased risk. For example, an insurance increase in the cost of gasoline would give a perverse incentive to increase risk by driving lighter vehicles that provide less occupant protection than heavier vehicles (Evans, 1991). 
Another problem for a gasoline surcharge system is the need for territorial classes to assess the difference in risk per VMT between urban and rural areas. If the insurance price per gallon could not be sufficiently varied by locale, which is likely because purchasing patterns would frustrate any but minimal differences, it would charge too little for the risk of driving done mainly in urban areas and too much for predominantly rural driving. As a consequence, there would be more urban driving than justified by accident costs, which would be subsidized by overcharging for the risk of rural driving. These difficulties in appropriate risk classification, largely ignored by proponents, are sufficiently serious that it is not necessary to examine important practical concerns. Therefore, we will consider alternatively how a system of per-mile insurance charges would probably operate, and how well it would perform the combined functions of exposure measurement and risk classification in comparison with the current system.

If required to change from the year to the vehicle mile exposure unit, auto insurance companies would probably follow standard commercial procedures (Butler, 1993a). This would include adopting the policy provisions on odometer fraud long since established by insurers in providing mechanical breakdown insurance for used cars. Premium payment in advance would be required to keep insurance protection in force. The premium at vehicle-mile prices for driving coverages would be prepaid in mileage amounts and at times chosen by the car owner. At a price of 5 cents per mile, for example, an owner might decide to spend $\$ 250$ to get 5,000 miles of coverage for the car, expecting that amount of protection to last about six months. Administrative expense and premium for non-driving coverages at vehicle year prices would be prepaid at policy-year renewal time. The car's proof-of-insurance identification card-required by law in most states-would display the odometer-mile and date limits at which protection would lapse pending further premium prepayment. Policy renewal would be conditional on taking the car to a garage designated by the company for the annual physical audit of its odometer. The odometer would be inspected and read, and tamperevident seals would be applied at the initial audit. Under this procedure, theft of insurance protection would be controlled because tampering with the odometer-a federal crime-would automatically void the policy. Driving with the odometer cable unhooked would not steal insurance protection, because it usually would be detected after an accident and the tampering would have voided the protection. Self-interest and competition on service should assure development of company systems that are efficient, convenient, and credible for consumers, and that effectively control premium fraud.

Although insurers have asserted in defense of current flat premiums that the costs of measuring mileage would be enormous, examination of their statements shows that the "mileage" to which they are referring is an expansion of declared-future "mileage rating" classes under the current vehicle year system. They are not referring to a system that would use an audited vehicle-mile exposure unit resulting in proportional premiums. Under cross examination at a rate discrimination trial, actuaries testifying as expert witnesses for defendant auto insurance companies admitted that, in their opinion, the cost of odometer auditing would be less than $\$ 25$. This amount, which is large in comparison with what private garages charge for safety and emissions inspections, is adopted for the sake of discussion in this paper. A study considering how a per-mile system probably would be operated found the potential for reducing the number of insurer transactions with customers from the current number ranging up to twelve per year for installment and suspension of coverage arrangements, and to reducing enforcement costs to states with mandatory coverage (Butler, 1993a). Since an odometer method capable of measuring exposure appears to be feasible, we can now consider the 
characteristics of current risk classes and how they could be converted to equivalent classes in a vehicle-mile system.

\section{CLASSIFICATION FOR MEASURING RISK PER VMT}

Of the five kinds of price classes cited, territory makes the greatest difference in what insurance now costs. A car's territory class is determined by the owner's residence and presumably assesses the risk where a preponderance of driving is likely to be done. This function can be evaluated by comparing two California territories where there is a large difference in prices, Table 2.

Table 2

Insurance Costs by Territory Class for Vehicle Miles Driven

\begin{tabular}{|c|c|c|c|c|c|c|}
\hline \multirow[t]{2}{*}{ Territory Class } & \multicolumn{2}{|c|}{$\begin{array}{l}\text { Vehicle-Year Price } \\
\text { (\$) by Future } \\
\text { Mileage Class* }\end{array}$} & \multicolumn{4}{|c|}{$\begin{array}{l}\text { Vehicle-Mile Cost (Cents) by } \\
\text { Miles Car Was Driven in Year }\end{array}$} \\
\hline & Low mi. & High mi. & $3,000 \mathrm{mi}$. & $8,000 \mathrm{mi}$. & $12,000 \mathrm{mi}$. & $20,000 \mathrm{mi}$. \\
\hline Rural N. Calif. & 229 & 265 & 7.6 & 3.3 & 2.2 & 1.3 \\
\hline Urban Los Angeles & 1,012 & 1,172 & 33.7 & 14.7 & 9.8 & 5.9 \\
\hline
\end{tabular}

* State Farm California manual effective 1-15-91. "Low" is future mileage stated as less than 7500 miles and "High" is 7500 miles and more.

State Farm's price for urban Los Angeles is 4.4 times the price it charges in thirteen rural Northern California counties for identical coverage, $\$ 1172$ versus $\$ 265$. Both prices reflect the declared future mileage class adjustments. For comparison to these annual prices, the costs to owners in cents-permile terms are calculated at four mileages from three to 20 thousand miles, each of which represents the amount many cars are driven in a year. (In 1990, about 15\% of household vehicles were driven less than 3,000 miles, and 18\% were driven more than 20,000 miles (Murakami, 1993).)

The justification for territorial classes is geographic variation in congestion and other hazards that affect per-mile accident rates. Using the analogy of accident involvement to random sampling, there is a higher accident-sampling rate per million VMT of urban class cars than of rural class cars. This rationale should be called into question, however, by what it now costs individuals per-mile for insurance protection.

The cost per mile under the existing system decreases as the number of miles driven during the policy year increases. In Table 2 the cost per mile is least for the cars driven 20,000 miles in one year. If the same 20,000 miles were driven in two years instead of one, however, the per-mile cost of insurance protection would double, from 1.3 cents to 2.6 cents in rural California, Table 2. Or if the 20,000 miles were driven in a year but two cars were used instead of one, the cost per mile, with the effect of a fifteen percent multi-car discount included, would nearly double to 2.3 cents. This large variation in insurance cost per mile within territory classes contradicts the rationale that territory classification assesses geographic differences in driving risk.

The driving risk rationale for territory classes is also challenged by comparing cents-per-mile insurance cost between Los Angeles and rural Northern California, where difference in driving risk presumably is very large. Paradoxically, however, insurance costs more per mile for rural California cars driven 
low mileages than it does for Los Angeles cars driven high mileages, 7.6 cents per mile for rural cars driven 3,000 miles in a year versus 5.9 cents per mile for urban cars driven 20,000 miles, Table 2. These kinds of anomalies in per-mile cost completely discredit the rationale of appropriate insurance pressure on the driving risk in different territories. Conversion of these two territorial classes to permile prices, however, shows how territorial classification could effectively assess difference in risk rates.

Conversion of auto insurance prices from the vehicle year to the vehicle mile unit requires determining the average mileage of each class. Cost per vehicle-year divided by miles per vehicle-year equals cost per vehicle-mile. Insurance companies now routinely determine cost per vehicle-year for each territory. They could closely estimate class-average mileages initially for conversion by sampling, but would subsequently get the average from the sum of the individual mileages of each class population. It is very unlikely, however, that the average annual mileage per vehicle in Los Angeles classes is the same as the average mileage in the comparable rural Northern California classes.

Because parking, taxes, and especially insurance make the unit cost of car ownership higher in cities, individual cars tend to be used by more drivers and the average annual miles per insured car should be more than in non-urban areas. Consequently, it is assumed that the urban Los Angeles class averages 12,000 miles per car year, which translates to a 9.8 cents per mile class-average cost, Table 2 . While rural drivers themselves probably average more miles than urban drivers, their driving is commonly spread over several vehicles. It is therefore assumed that the rural California class average is 8,000 miles per vehicle, which results in a 3.3 cents per mile class cost. By means of these per-mile averages, the effect on annual insurance expenditure through conversion from per-year prices can be considered.

\section{Figure 1}

Flat and proportional premiums by vehicle miles traveled per year for urban and rural territories

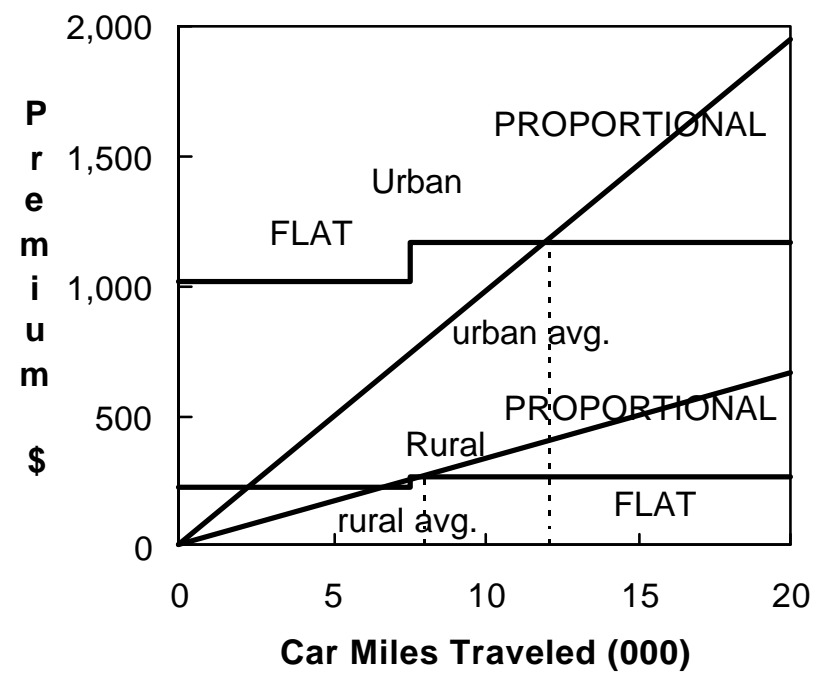

Figure 1 shows the effect on premium charges of the miles a vehicle travels during a policy year. Stepped horizontal lines represent the premium cost at the current dollars per year prices for the two 
territories. Steps at 7,500 miles show the effect of the two future mileage classes, as if they represented the miles subsequently driven during the policy year. The two "proportional" lines extending from the origin represent the premium versus vehicle miles traveled at per-mile prices. The slopes are defined by the current premium divided by the average mileages assumed for each class (Table 2). These mileages are marked by vertical lines, which connect to the equal premium intersections of the Flat and Proportional lines. Owing to the different average mileages assumed for the classes, the slope of the Urban line is only about three times as steep as the Rural line, which probably represents a more realistic difference in risk per mile than the 4.4 to one ratio of the flat premiums. Comparing flat and proportional premium lines also allows us to consider some implications of a change to the vehicle mile exposure unit.

\section{IMPLICATIONS OF EXPOSURE UNIT CHANGE}

\section{INCENTIVE TO CONTROL RISK}

The existing insurance pressure on ownership cost perversely provides incentives for increased risk. The only way consumers have to cut insurance expense-other than by selling one car and using another more intensively or by keeping a young household member from getting a license-is to cut back on coverage. But reducing coverage increases the risk to family savings, and shifts costs to employer paid health insurance and to social insurance funded by taxpayers.

It is axiomatic that, with every mile a car is driven, risk is both assumed by the car's owner and passengers and is also imposed on other road users. With reference to the flat premium lines of Figure 1, the effect of insurance cost on the amount of driving is limited to the extent that income to pay the cost of gasoline is reduced by the insurance charge. Nevertheless, once the lump sum insurance cost of admission to car registration is paid-whether $\$ 1,000$ in Los Angeles or onequarter of that in rural California-insurance cannot put cost pressure on decisions about whether or not to take a trip. The relatively small step up for the high future mileage class merely serves as an incentive to avoid the step by declaring a low future mileage on the application or renewal form. Just as price competition has dictated over the past decade for car rentals, auto insurance provides "unlimited free mileage."

In contrast to the current lack of insurance incentive to limit exposure to accident risk, proportional premiums would impose cost pressure on every mile driven. After paying a nominal fee for odometer auditing, the incremental (marginal) cost that per-mile insurance would provide is like the resistance to walking up an incline, up the proportional premium line. The steepness of proportional premium lines in Figures 1 signals the degree of driving risk with per-mile prices. Higher risk classes would put more cost pressure on the amount of driving. Young drivers cannot increase their age, nor should people be expected to move to lower risk rate territories, but proportional premiums would allow drivers to control their insurance cost, the same way they can control their accident risk, by the amount of driving they do.

Risk is strongly affected by vehicle weight (Evans, 1991, pp. 64-77, 94-95) and, to a lesser extent, by safety devices like air bags and anti-lock brakes. Existing premiums, however, do not vary at all by car weight. Furthermore, the discounts insurance companies provide for safety devices on late model cars are not only not backed by claim cost experience, but also may be associated with more collision and injury claims per car year than identical cars without the optional devices (Peterson and Hoffer, 
1996). Although "offsetting behavior" and "adverse selection" (drivers with higher risk per-mile somehow know this and preferentially buy safety equipment) are offered as explanations (Peterson and Hoffer 1996), it is also true that demand for optional safety devices correlates directly with income which also positively relates to demand for vehicle miles of travel, that is, exposure to risk. More miles of travel on average by those choosing anti-lock brakes would tend to offset any reduction in risk rate per mile.

Drivers can reduce their risk rate through choice of a heavier car at a cost of decreased fuel efficiency and increased risk per mile imposed on other traffic. The current flat premium system, however, provides no accurate financial risk-reducing incentive or even any information on what car weight is most risk-efficient in terms of the combined effect of assumed and imposed risk.

\section{INDIVIDUAL AND GROUP EFFECTS}

Which individuals and groups would spend less and which would spend more on insurance with a change from flat to proportional premiums? This issue can be framed with reference to Figure 2, which is a simplified version of Figure 1. It shows premium paid as a function of miles traveled during the policy year. The $\$ 500$ premium line has no steps for future mileage classes, in view of their inherent unenforceability. A class average 10,000 miles per year is assumed, which makes the slope of the proportional premium line 5 cents per mile. An odometer audit fee--assumed generously at $\$ 25$ for the sake of discussion--raises the proportional line by that amount and puts the equal premium intersection of the two lines at 9,500 miles (the $\$ 25$ fee is equivalent to 500 miles at 5 cents per mile).

\section{Figure 2}

Flat and proportional premiums by vehicle miles traveled per year with $\$ 25$ assumed odometer fee

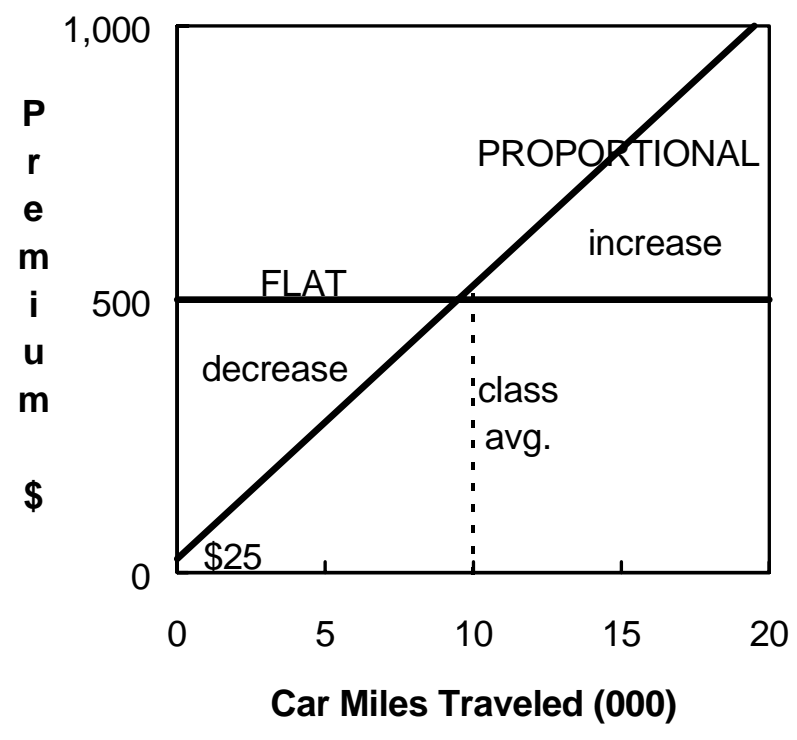

The vertical separation between the flat and proportional lines at the number of miles actually driven represents the change in insurance expense with change in exposure unit. This helps to answer the question I posed initially in observing that ownership cost would decrease for all drivers-by a net of 
$\$ 475$ in Figure 2-but that the simultaneous insurance increase in operating cost would be greater or less than the ownership cost reduction. The answer for individuals would depend on whether they drive more or less after the change than what the average mileage for their class was before the change. We can draw some conclusions about groups by considering conditions that now cause changes in driving levels.

For Figure 1 we assumed a difference in average mileage between rural and urban territories in California. In estimating the number of future claims, insurers take into consideration expected economic conditions and gasoline prices. During recessions, or when the price of gasoline increases significantly, many drivers reduce the number of trips they take with the result that overall accidents and claims drop sharply (Butler et al., 1988, p. 272). At a hearing by the Pennsylvania House insurance committee when the 1990-1991 recession was ending, the President of the Insurance Federation of Pennsylvania testified that auto claims had declined not because of a recent reform law to control medical expense, but because of decreased driving. To dramatize the relatively large drop in auto insurance claims, he quoted State Farm's Pennsylvania vice president as speculating that "a lot of cars are up on blocks" (Hager, 1991).

When the economy improves or gasoline gets cheaper, auto insurers apply for regulatory approval of higher prices because "people are driving more" (see Butler et al., 1988, pp. 272-273 for statements made to regulators). The fact that insurers find it necessary to raise prices when driving increases is strong evidence that current automobile premiums do not respond to the individual changes that add up to changes in average mileage.

Although insurers usually retain the windfall decreases in costs from unexpected decreases in driving as a hedge against having to raise prices sharply when driving returns to normal, occasionally they refund part of the surplus premium. For example, refunds by State Farm Mutual Auto Insurance that followed the 1990-1991 recession illustrate the cost-shifting effects of the current price system. At the end of policy periods covering that time interval, in several states the company returned 20 percent of the premium that each policy holder initially paid (News report, 1991).

Figure 3 reproduces Figure 2, but with the effect of a 20 decrease in insurer cost represented by a premium refund. It also shows an assumed proportional decrease in average mileage from 10,000 to 8,000 miles. If 20 percent is the average decrease in driving, and if it is assumed that there are drivers not affected by recessions or gasoline prices, then some of those who were affected must have decreased driving more than 20 percent. Drivers who cut mileage thirty percent got a twenty percent refund along with all other car owners. The other ten percent savings would thus pay for the refund to owners who cut driving less than 20 percent, or may even have increased their driving. 
Figure 3

Effect of twenty percent decrease in average mileage on flat versus proportional premiums

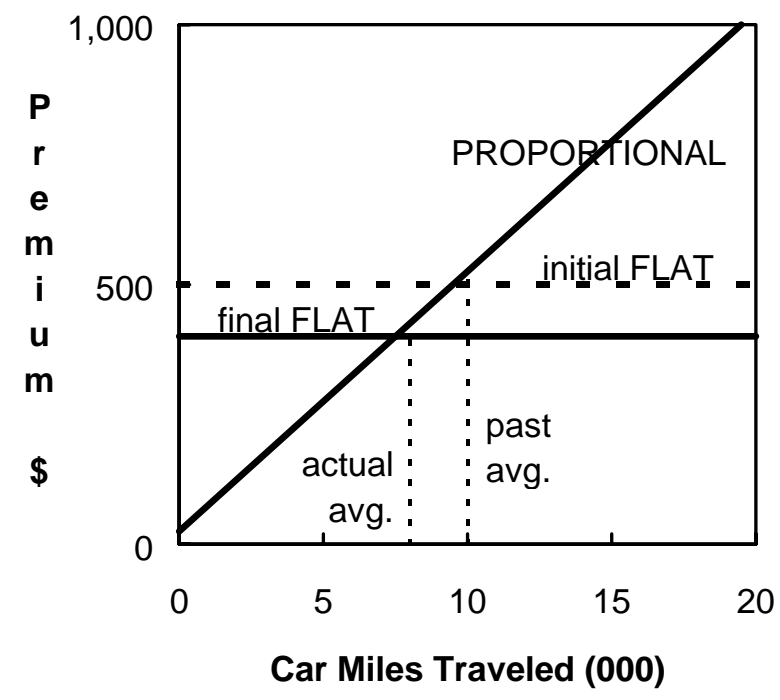

Thus with current pricing based on class-average cost, any windfall cost reduction from a decrease in average mileage actually goes not just to people who drive less, but is spread to all policyholders regardless of their individual mileage. Those who are responsible for cost savings share them with others unaffected by recessions and higher gasoline prices. Since demand for vehicle miles correlates to income (Dahl, 1986), dollars in effect are transferred from lower to higher income motorists via auto insurance premiums. Car owners whose mileage is perennially below average are forced to subsidize the insurance protection for owners of cars in their class driven above average mileage. Low income individuals who buy car insurance they can scarcely afford in fact subsidize premiums for those who generally do not need the subsidy.

\section{WOMEN AND MEN}

Economic conditions and the price of gasoline must also differentially affect the driving of women and men as two demographic groups with a large difference in income distributions. In 1990, 41 percent of women drivers drove less than 5,000 miles, while about half as many men drivers were in this low mileage category (Hu and Young, 1993, p. 3-20). Conversely, in the high mileage category, nearly $30 \%$ of men drove more than 20,000 miles while only $11 \%$ of women drove that much, Figure 4. The difference between the mileage distributions of women and men leaves little doubt that a greater proportion of women than men would gain a deserved and risk-based net saving from a change from per year to per mile insurance. Nevertheless, it is important to keep in mind that it is individuals, not groups, who drive cars and that individuals respond differently to changes in the cost of driving and also to changes in economic conditions. 
Figure 4

1990 NPTS distribution of women and men drivers by annual mileage

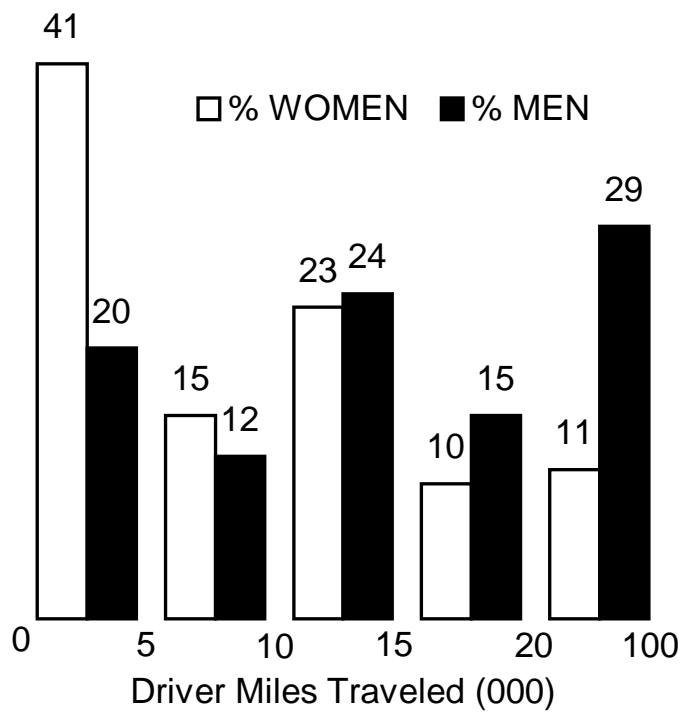

Current flat pricing is buttressed by strong insurer marketing mythologies. Prime examples are the selective reality of women's greater "safety" as drivers and the statistically absurd idea that risk can be individually assessed by use of driver-record and claim-free pricing. Moreover, recent research on women drivers has sought to problematize the increase in women's annual accident involvement, rather than to explain it as an inevitable consequence of an increase in women's average miles of exposure to accident risk. Press releases announcing research findings generate invidious newspaper headlines like "Road hazard? Women are more accident-prone, U-M study finds" (Greenwood, 1993).

Academics inexcusably ignore past criticism of the auto insurance price structure. For example, in a 1968 law and economics study, one of this year's Nobel prize winners, William Vickrey, attempted to call attention to "the frequently overlooked fact that the manner in which premiums are computed and paid fails miserably to bring home to the automobile user the costs he imposes in a manner that will appropriately influence his decisions" (Vickrey, 1968). Subsequent scholarly indifference to this strong condemnation can only be explained in terms of protecting a subsidy for higher-mileage drivers as a politically and economically powerful group. University researchers, however, have a responsibility to set aside class and sex politics. They need to contribute constructively to an emerging and long overdue critique of the practice of charging for automobile insurance as a fixed cost of car ownership rather than as a variable cost of car use, the activity that produces traffic accidents. 


\section{REFERENCES}

Brown, R. L. 1995. "Recent Canadian Human Rights Decisions Having an Impact on Gender-Based Risk Classification Systems.” Journal of Actuarial Practice 3: 171-180.

Butler, P. 1993a. "Operation of an Audited-Mile/Year Automobile Insurance System Under Pennsylvania Law.” Casualty Actuarial Society Forum Summer 1993: 307-338.

Butler, P. 1993b. "Cost-Based Pricing of Individual Automobile Risk Transfer: Car-Mile Exposure Unit Analysis." Journal of Actuarial Practice 1: 51-84.

Butler, P. 1995. "Discussion of Robert L. Brown's 'Recent Canadian Human Rights Decisions Having an Impact on Gender-Based Risk Classification Systems."' Journal of Actuarial Practice 3: 181-190.

Butler, P. and T. Butler. 1989. "Driver Record: a Political Red Herring That Reveals the Basic Flaw in Automobile Insurance Pricing." Journal of Insurance Regulation 8: 200-234.

Butler, P., T. Butler, and L. L. Williams. 1988. "Sex-Divided Mileage, Accident, and Insurance Cost Data Show That Auto Insurers Overcharge Most Women." Journal of Insurance Regulation 6: 243-284 (Pt. I), 373-420 (Pt. II).

Calabresi, G. 1970. The Costs of Accidents: A Legal and Economic Analysis. New Haven: Yale University Press.

Cardoso, R. 1993. "Discussion of Patrick Butler's 'Cost-Based Pricing of Individual Automobile Risk Transfer: Car-Mile Exposure Unit Analysis."” Journal of Actuarial Practice 1: 69-71.

Dahl, C. A. 1986. "Gasoline Demand Survey.” The Energy Journal 7: 67-82.

Evans, L. 1991. Traffic Safety and the Driver. New York: Van Nostrand Reinhold.

Greenwood, T. 1993. "Road hazard? Women are more accident-prone." The Detroit News, July 9, 1993, p. 1A.

Hager, H. 1991. "Insurance Federation of Pennsylvania Testimony." Insurance Committee, Pennsylvania House of Representatives. Hearing Transcript, November 14, 1991: 109-125.

Hu, P. S. and J. Young. 1993. 1990 NPTS Data Book, Nationwide Personal Transportation Survey. Volume I.

Industry Advisory Committee (to the National Association of Insurance Commissioners). 1979. "Driving Record." Report: Private Passenger Automobile Insurance Risk Classification. Part G, 43-66.

Murakami, E. 1993. Table of model year by annualized vehicle miles, June 28, 1993.1990 Nationwide Personal Transportation Survey (NPTS).

National Organization for Women. 1998. "Model Per Mile Auto Insurance Option Act." www.now.org/issues/economic/insurancel 
News report. 1991. "State Farm to Refund Millions in Car Premiums." Journal of Commerce, December 18, p. 9A.

Peterson, S. and G. E. Hoffer. 1996. "Auto Insurers and the Air Bag: Comment." Journal of Risk and Insurance 63: 515-523.

Sugarman, S. D. 1993. "Pay at The Pump" Auto Insurance. Berkeley: Institute of Governmental Studies Press, University of California.

Vickrey, W. 1968. "Automobile Accidents, Tort Law, Externalities, and Insurance: An Economist's Critique." Law and Contemporary Problems 33: 464-487.

Williamson, O. E., D. G. Olson, and A. Ralston. 1967. "Externalities, Insurance, and Disability Analysis." Economica 34: 235-253. 